\title{
Quantitative Determination of Total L-Carnitine in Infant Formula, Follow-up Formula, and Raw Materials by Liquid Chromatography with Tandem Mass Spectrometry
}

\author{
Isao Nadaoka, ${ }^{* \dagger}$ Emi Hatakeyama, ${ }^{*}$ Chihiro Tanada, ${ }^{* *}$ Tasuku Sakamoto, ${ }^{* *}$ Shinichi Fukaya, ${ }^{*}$ \\ Takashi AKIBA, ${ }^{*}$ Koichi InOUE, ${ }^{* *}$ Yutaka YAMANo, ${ }^{*}$ and Toshimasa ToYo’oKA** \\ *Department of Infant Milk and Analytical Technology, Research and Development Center, Wakodo Co., Ltd., \\ 2-2 Wakaba, Chofu, Tokyo 182-0003, Japan \\ **Laboratory of Analytical and Bio-Analytical Chemistry, School of Pharmaceutical Sciences, University of \\ Shizuoka, 52-1 Yada, Suruga, Shizuoka 422-8526, Japan
}

\begin{abstract}
We developed a rapid and useful routine screening assay for total L-carnitine content in various infant formulas and materials by liquid chromatography coupled with a tandem mass spectrometric method (LC-MS/MS) and alkaline hydrolysis. For separation of L-carnitine, a multi-mode octadecylsilane (ODS) column was used that contained ODS ligands, anion ligands, and cation ligands to avoid using ion-pairing agents. The stable isotope L-carnitine- $d_{3}(\mathrm{~m} / z, 165 \rightarrow$ 103/85) was used in electrospray MS/MS in the multiple reaction monitoring mode with the ion transitions of $\mathrm{m} / \mathrm{z}, 162 \rightarrow$ 103/85 for detection and quantitation of L-carnitine. Alkaline hydrolysis of short/medium chain (C2 - C15) acyl-Lcarnitines in infant formula was analyzed by LC with quadrupole time-of-flight mass spectrometry (QTOF-MS). The majority of short/medium chain acyl-L-carnitines were hydrolyzed to free L-carnitine. The overall standard deviations for L-carnitine in infant formula, follow-up formula and raw materials ranged from 2.1 to 4.0. The overall mean recoveries ranged from 90.2 to $94.2 \%$.
\end{abstract}

Keywords LC-MS/MS, L-carnitine, infant formula, raw materials, multi-mode ODS column

(Received March 10, 2014; Accepted June 10, 2014; Published August 10, 2014)

\section{Introduction}

L-Carnitine (3-hydroxy-4- $N$-trimethylaminobutyric acid, Fig. 1) is an essential component of animal tissues, higher plants, and many microorganisms and is well recognized as having a fundamental role in lipid metabolism. This lipid metabolism is consistent with an increase in fatty acid $\beta$-oxidation and/or an enhancement in lipoprotein with the transport of long-chain fatty acids into the inner mitochondrial matrix in the form of acyl-carnitines as coenzyme A (CoA) esters. An additional role of L-carnitine in lipid metabolism is removal of potentially toxic short- and medium-chain acyl-CoA esters from mitochondria. ${ }^{1,2}$ L-Carnitine is a non-protein amino acid available to humans both through in vivo biogenesis involving lysine and methionine and from a variety of dietary sources, notably meat and dairy products. ${ }^{3,4}$ In infants, this non-protein amino acid is an essential nutrient because they are unable to synthesize L-carnitine because of an immature biosynthesis pathway. ${ }^{1,5}$ Human milk is reported to contain $0.5-1.5 \mathrm{mg} / 100 \mathrm{~g}$ L-carnitine, which is sufficient to maintain normal plasma concentration, but is lower than that of bovine milk $(2.5-4.3 \mathrm{mg} / 100 \mathrm{~g}) .{ }^{6.7}$ Therefore bovine milk-based formulas should generally meet the nutritional needs of infants unless L-carnitine concentrations are

$\dagger$ To whom correspondence should be addressed.

E-mail: nadaokai@wakodo.co.jp altered during manufacturing. However, certain bovine milk-based formulas assembled from depleted raw materials and all soy-based formulas are potentially L-carnitine deficient and may require supplementation. ${ }^{1}$ The need to fortify infant formula with L-carnitine has been recognized since the late 1970 s or the early 1980s. ${ }^{8}$ Human and bovine milk are composed of free L-carnitine, short/medium chain acyl-Lcarnitines (acid soluble), and long chain acyl-L-carnitines (acid insoluble). Long chain acyl-L-carnitines reportedly contribute $2-3 \%$ in milk; thus, quantitation of total L-carnitine content is commonly performed for free L-carnitine and short/medium chain acyl-L-carnitines. ${ }^{3,9-11}$ To quantitate the total amount of L-carnitine content in milk, it is necessary to perform alkaline hydrolysis of short/medium chain acyl-L-carnitines. ${ }^{12}$ We have previously reported the optimal alkaline hydrolysis conditions of short/medium chain acyl-L-carnitines. ${ }^{13}$ In this study, we

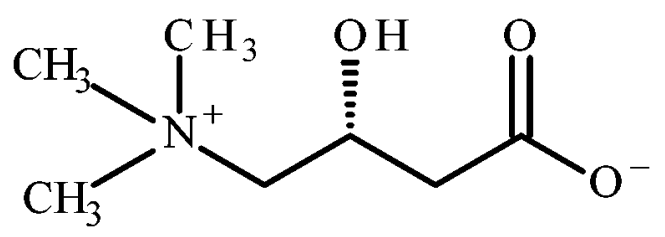

Fig. 1 Chemical structure of L-carnitine. 
used quadrupole TOF-MS with accurate mass analysis to evaluate the alkaline hydrolysis behavior of short/medium chain (C2 - C15) acyl-L-carnitines in infant formula and follow-up formula under our optimal conditions.

In earlier reports, L-carnitine in milk and infant formulas has traditionally been determined by enzymatic assays, which were adapted from earlier methodologies for clinical determinations of L-carnitine in body fluids and tissues. Marquis et al. developed an enzymatic assay of L-carnitine in rat tissues based on the following reaction (1) catalyzed by carnitine acetyltransferase. ${ }^{14}$

$$
\text { L-carnitine }+ \text { acetyl-CoA } \rightleftharpoons \text { acetyl-L-carnitine }+ \text { CoA }
$$

After the reaction, the concentration of L-carnitine was determined indirectly by generating a color reaction between free $\mathrm{CoA}$ and 5,5'-dithiobis-(2-nitrobenzoic acid). ${ }^{11}$ In recent years, efficient, stable, and useful systems using LC techniques $^{15,16}$ and LC-MS/MS of individual carnitine species $^{17,18}$ have been developed. For the LC analysis of L-carnitine, researchers have commonly used ion-pairing agents added to the mobile phase that reduce the polarity of L-carnitine and make it more suitably retained on reversed-phase stationary phases. $^{18,19}$ Although ion-pairing LC can improve the retention and selectivity of hydrophilic ionic and/or ionizable analytes, it often requires long equilibration times, a dedicated column, and usually an MS-incompatible mobile phase. Thus, a mixedmode stationary phase utilizing simultaneous reversed-phase and ion exchange functionalities was used to increase the retention of L-carnitine without any mobile phase ion-pair additives. In recent work, a mixed-mode stationary phase and mass spectrometric detection with stable isotope dilution was applied for the determination of L-carnitine in infant formula. ${ }^{20}$ A few methods using LC-MS/MS and/or LC-MS with stable isotope dilution have been used in attempts to quantitate L-carnitine content in infant formula. ${ }^{18-20}$ In this study, we used 15 min alkaline hydrolysis, a multi-mode octadecylsilane (ODS) column, ${ }^{20,21}$ LC-MS/MS with a stable isotope standard, and developed a more rapid routine method for quantitative determination of total L-carnitine content in infant formulas, follow-up formulas, and raw materials.

\section{Experimental}

\section{Reagents and chemicals}

Analytical standard L-carnitine hydrochloride (98\%) and acetyl-L-carnitine hydrochloride (99\%) were obtained from Sigma-Aldrich (St. Louis, MO). Internal standard (IS) L-carnitine- $d_{3}$ hydrochloride $(99.9 \%)$ was obtained from $\mathrm{C} / \mathrm{D} / \mathrm{N}$ Isotopes (Quebec, Canada). Acetonitrile, formic acid, and ammonium formate were of LC-MS grade from Sigma-Aldrich. Perchloric acid $\left(\mathrm{HClO}_{4}\right)$, hydrochloric acid $(\mathrm{HCl})$, and potassium hydroxide $(\mathrm{KOH})$ were of analytical grade from Wako Pure Chemical Industries, Ltd. (Osaka, Japan). Water was processed through a Milli-Q purification system (Merck Millipore, Billerica, MA). L-carnitine standard stock solution of $320 \mu \mathrm{g} / \mathrm{mL}$ was prepared by dissolving $40 \mathrm{mg}$ of L-carnitine hydrochloride in $100 \mathrm{~mL}$ of water and stored at $-20^{\circ} \mathrm{C}$ for 1 year. An intermediate standard solution of $800 \mathrm{ng} / \mathrm{mL}$ was obtained by diluting the stock solution 400 times with water. L-carnitine working solutions were prepared in appropriate concentrations by diluting the intermediate standard solution with water and were stored at $4{ }^{\circ} \mathrm{C}$. IS stock solution of $820 \mu \mathrm{g} / \mathrm{mL}$ was prepared by dissolving $10 \mathrm{mg}$ of L-carnitine- $d_{3}$ hydrochloride in $10 \mathrm{~mL}$ of water and stored at $-20^{\circ} \mathrm{C}$ for 1 year. IS working solution of $820 \mathrm{ng} / \mathrm{mL}$ was obtained by diluting the stock solution 1000 times with water and stored at $-20^{\circ} \mathrm{C}$ for 1 year.

\section{Milk samples}

Infant formula and follow-up formulas were manufactured by Wakodo Co., Ltd. (Tokyo, Japan) for the recovery and validation. In addition, other common infant and follow-up formulas and whole milk powder, skim milk powder, and whey protein concentrate powder were obtained from Japanese or foreign markets. Standard reference material (SRM) 1849a (the certified mass fraction value of total L-carnitine content was $13.6 \pm 1.4 \mathrm{mg} / 100 \mathrm{~g}$ ) was obtained from the National Institute of Standards and Technology (NIST).

\section{Sample preparation for total L-carnitine content}

Samples were prepared by dissolving $1.5 \mathrm{~g}$ infant or follow-up formula, $1.0 \mathrm{~g}$ whole milk powder or skim milk powder, and $0.25 \mathrm{~g}$ whey protein concentrate powder in $15 \mathrm{~mL}$ warm $\left(50^{\circ} \mathrm{C}\right)$ water in a $50-\mathrm{mL}$ glass beaker. A $5.0-\mathrm{mL}$ aliquot of $1.2 \mathrm{M}$ $\mathrm{HClO}_{4}$ solution was added and mixed thoroughly, and the sample was filtered through a No. 5B filter paper (Advantec, Dublin, CA) into a 50-mL volumetric flask. The glass beaker was washed with $0.3 \mathrm{M} \mathrm{HClO}_{4}$ solution, filtered twice, and filled to $50 \mathrm{~mL}$ with water. A $10-\mathrm{mL}$ aliquot of the filtrate was added to $20 \mathrm{~mL}$ of $0.2 \mathrm{M} \mathrm{KOH}$ solution and allowed to stand for $15 \mathrm{~min}$ at $40^{\circ} \mathrm{C}$. The $\mathrm{pH}$ was adjusted to $7.0 \pm 0.5$ with $1.0 \mathrm{M} \mathrm{HCl}$ solution. The solution was transferred to a $50-\mathrm{mL}$ volumetric flask and brought to volume with water. A $100-\mu \mathrm{L}$ aliquot was mixed with $50 \mu \mathrm{L}$ of the IS working solution and $850 \mu \mathrm{L}$ of water and then filtered through a $0.20-\mu \mathrm{m}$ polytetrafluoroethylene syringe filter (Merck Millipore) before LC-MS/MS analysis.

\section{LC-MS/MS analysis}

An acquity ultra performance LC system coupled to a Xevo TQ MS triple quadrupole MS with an ESI source (Waters, Milford, MA) was used to perform the analyses. The column oven temperature was set at $40^{\circ} \mathrm{C}$, and the autosampler temperature was set at $10^{\circ} \mathrm{C}$. The injection volume was $5 \mu \mathrm{L}$. Separation was achieved on a Scherzo SS-C18 $(100 \mathrm{~mm} \times 2.0$ mm i.d., $3.0 \mu \mathrm{m}$ ) column (Imtakt, Kyoto, Japan) with mobile phase A consisting of $0.3 \%$ formic acid aqueous solution and mobile phase $\mathrm{B}$ consisting of $100 \mathrm{mM}$ ammonium formate aqueous solution/acetonitrile $(50: 50, \mathrm{v} / \mathrm{v})$. The flow rate was set at $0.3 \mathrm{~mL} / \mathrm{min}$. A linear gradient was used with the following parameters: $10-30 \% \mathrm{~B}$ from 0 to $5 \mathrm{~min}, 30-90 \% \mathrm{~B}$ from 5 to $6 \mathrm{~min}, 90 \% \mathrm{~B}$ from 6 to $9 \mathrm{~min}$, and $90-10 \% \mathrm{~B}$ from 9 to $10 \mathrm{~min}$. To achieve maximum sensitivity for the analytes, the analysis was performed in the positive ion mode. Nitrogen was used as the nebulizer gas. The parameters for ESI-MS were as follows: capillary voltage, $3.5 \mathrm{kV}$; source temperature, $150^{\circ} \mathrm{C}$; desolvation temperature, $350^{\circ} \mathrm{C}$; desolvation gas flow, $800 \mathrm{~L} / \mathrm{h}$; and cone gas flow, $50 \mathrm{~L} / \mathrm{h}$. Cone voltages and collision energies were optimized for the analytes. The multiple reaction monitoring (MRM) mode was used to perform quantitative analysis. L-carnitine transitions were $\mathrm{m} / \mathrm{z} 162>103$ and $162>$ 85. IS transitions were $m / z, 165>103$ and $165>85$. The LC-MS/MS instrument was controlled by the MassLynx and Quanlynx software (Version 4.1, Waters).

LC-QTOF-MS analysis for investigation of alkaline hydrolysis of short/medium chain acyl-L-carnitines

An Agilent Technologies 1200 Series LC system was used 
(Santa Clara, CA). The conditions were as described above. The detector was an Agilent 6510 QTOF-MS equipped with an ESI source. The instrument was operated with the ESI source in the positive ion mode. The following conditions were used: Vcap voltage, $3500 \mathrm{~V}$; fragmentor voltage, $120 \mathrm{~V}$; skimmer voltage, $65 \mathrm{~V}$; OCT 1 RF voltage, $750 \mathrm{~V}$; drying gas flow, $10 \mathrm{~L} / \mathrm{h}$; nebulizer, $45 \mathrm{psig}$; and gas temperature, $300^{\circ} \mathrm{C}$. The MS monitoring range was from $\mathrm{m} / \mathrm{z}, 50$ to 1500 using a reference mass solution (API-ROF Reference Mass Solution Kit, hexakis, purine, and ammonium trifluoroacetate from Agilent Technologies) for the identification of short/medium chain acylL-carnitines in infant formula or follow-up formula.

\section{Calibration curves and quantitation of L-carnitine}

L-Carnitine calibration standards were prepared at six concentration levels, $8,16,40,80,160$, and $320 \mathrm{ng} / \mathrm{mL}$, each containing $40 \mathrm{ng} / \mathrm{mL}$ IS. The MRM chromatogram for L-carnitine was a sum of signals for the transitions $\mathrm{m} / \mathrm{z} 162>$ 103 and $162>85$. Similarly, the MRM chromatogram for the IS was a sum of signals for the transitions $\mathrm{m} / \mathrm{z}, 165>103$ and $165>85$. The QuanLynx software automatically calculated a response ratio, defined as the L-carnitine peak area divided by the IS peak area. Additionally, the software automatically plotted L-carnitine standard curves and calculated the concentration $(\mathrm{ng} / \mathrm{mL})$ of L-carnitine in the samples. We used the following equation to calculate the concentration $(\mathrm{mg} / 100 \mathrm{~g})$ of L-carnitine in milk powder: L-carnitine concentration $(\mathrm{mg} / 100 \mathrm{~g})=\mathrm{L}$-carnitine concentration. $(\mathrm{ng} / \mathrm{mL}) /$ sample weight $(\mathrm{g}) \times 0.25$.

\section{Method validation}

Validation experiments were performed in a single laboratory on a single LC-MS/MS instrument. Linearity was evaluated against a calibration curve $(n=10)$. Precision was evaluated by repeatability. Repeatability was calculated from the analyses of infant formula, follow-up formula, raw materials, and SRM 1849a in duplicate on each of six days. Accuracy was evaluated by analysis of SRM 1849a and by performing spike recovery studies with infant formula, follow-up formula, and raw materials in duplicate on each of three days. In the recovery studies, each sample was fortified with L-carnitine reference standard at approximately $100 \%$ of the L-carnitine amount in each unspiked sample. Each sample was fortified with acetyl-Lcarnitine at approximately $100 \%$ of the L-carnitine amount in each unspiked sample. The following equation was used to calculate the recoveries for each spiked sample:

Recovery $(\%)=[($ empirical spiked concentration average empirical unspiked concentration)/theoretical spiked concentration] $\times 100$

Each average empirical unspiked concentration was the average L-carnitine concentration of each unspiked sample in the precision studies. Detection and quantitation limits were not validated because all milk powders contained concentrations of L-carnitine well above these limits.

Determination of total L-carnitine content in commercial infant formulas and follow-up formulas

Twelve commercial products were collected from retail outlets, and their total L-carnitine content was determined by the described procedures.

\section{Results and Discussion}

\section{Sample preparation}

For quantitation of total L-carnitine content in infant formula, follow-up formula, and raw materials, it is necessary to remove protein and perform alkaline hydrolysis of short/medium chain acyl-L-carnitines. The alkaline hydrolysis conditions must assure that only short/medium chain acyl-L-carnitines are hydrolyzed and that L-carnitine is not decomposed. We have previously reported the optimal alkaline hydrolysis conditions for infant formula, follow-up formula, and raw materials. The optimal alkaline hydrolysis conditions are $0.2 \mathrm{M} \mathrm{KOH}$ solution (sample solution $\mathrm{pH} 13$ ) at $40^{\circ} \mathrm{C}$ for $15 \mathrm{~min} .{ }^{13}$ In this study, alkali-hydrolyzed short/medium chain acyl-L-carnitines were investigated in infant and follow-up formulas; LC-QTOF-MS was used for the analysis, and accurate $\mathrm{m} / \mathrm{z}$ values were calculated against standards. The $\mathrm{m} / \mathrm{z}$ values, accurate mass results (ppm), and detection levels of short/medium chain acyl-L-carnitines are shown in Table 1. In the infant and follow-up formula samples, short/medium chain acyl-Lcarnitines were of $\mathrm{C} 1, \mathrm{C} 2, \mathrm{C} 3, \mathrm{C} 4, \mathrm{C} 5$, and $\mathrm{C} 8$ types. The results showed that short/medium chain acyl-L-carnitines from $\mathrm{C} 1$ to $\mathrm{C} 4$ were completely hydrolyzed under the conditions used in the LC-QTOF-MS chromatogram. Most peaks were not detected (peak response $<5000$ ). In the case of C5 in the infant and follow-up formula samples, the peak responses were markedly decreased by 60 and $62 \%$, respectively. On the other hand, the peak responses of $\mathrm{C} 8$ in the infant and follow-up formula samples without hydrolysis were 9460 and 7237, respectively, which represented lower concentration levels of medium chain acyl-L-carnitines of the C8 type. Because the unhydrolyzed sample peak levels were so low, the peaks of hydrolyzed $\mathrm{C} 8$ would not be detected in this system. Thus, the total short/medium chain acyl-L-carnitines were mostly changed to free L-carnitine. With respect to the hydrolysis conditions, several conditions have been reported; $1 \mathrm{M} \mathrm{KOH}$ solution at $40^{\circ} \mathrm{C}$ for $60 \mathrm{~min},{ }^{11} 2 \mathrm{M} \mathrm{KOH}$ solution at $50^{\circ} \mathrm{C}$ for $30 \mathrm{~min},{ }^{18}$ and $1 \mathrm{M} \mathrm{HCl}$ solution at $110^{\circ} \mathrm{C}$ for $15 \mathrm{~min}^{20}$ In comparison with these conditions, our optimal alkaline hydrolysis conditions are more safe, rapid and useful for the routine quality control assay of various formula samples.

\section{LC-MS/MS analysis of L-carnitine}

We used a multi-mode ODS column that contained ODS ligands, anion ligands, and cation ligands. The biggest benefit of the multi-mode columns was that the selectivity could be optimized by adjusting the mobile phase ionic strength, $\mathrm{pH}$, and/or organic solvent. Consequently, these columns are not only complementary to reversed-phase columns but also provide different selectivities under different conditions. ${ }^{22-25}$ The presence of both reversed-phase and ion-exchange functionalities requires no ion-pairing agent in the mobile phase to separate highly hydrophilic charged analytes, thus simplifying the mobile phase and making the method compatible with MS. ${ }^{20,21}$ Previous reports suggest that mixed-mode columns capable of both reversed-phase and ion-exchange separation modes can be of some value for improved separation of polar substances. ${ }^{26,27}$ Actually, these columns with gradient mode showed significant improvements in the peak shape of oligonucleotides. ${ }^{26}$ Moreover, Stevenson et al. indicated that the retention mechanisms of these columns were changed under these $\mathrm{pH}$ environments for the mobile phase. ${ }^{27}$ In this study, the separation of L-carnitine was investigated based on these reports. Mobile phase A was $0.3 \%$ formic acid aqueous solution and mobile 
Table 1 Analysis of the alkaline hydrolysis of short/medium chain (C2 - C15) acyl-L-carnitines in infant formula and follow-up formula by LC-QTOF-MS

\begin{tabular}{|c|c|c|c|c|c|c|c|c|}
\hline \multirow{3}{*}{$\begin{array}{l}\text { Short/medium } \\
\text { chain } \\
\text { acyl-L-carnitines }\end{array}$} & \multirow{3}{*}{$\frac{M_{\mathrm{W}}{ }^{\mathrm{a}}}{\text { Average }}$} & \multirow{3}{*}{$\begin{array}{c}M_{\mathrm{W}} \\
\text { Mono }\end{array}$} & \multirow{3}{*}{$\begin{array}{c}\begin{array}{c}\text { Calculated } \\
m / z \text { value }\end{array} \\
{[\mathrm{M}+\mathrm{H}]^{+}}\end{array}$} & \multirow{3}{*}{$\begin{array}{c}\begin{array}{c}\text { Actual } \mathrm{m} / \mathrm{z} \\
\text { value }^{\mathrm{b}} / \mathrm{ppm}^{\mathrm{c}}\end{array} \\
{[\mathrm{M}+\mathrm{H}]^{+}}\end{array}$} & \multicolumn{4}{|c|}{ Detected $m / z$ value/ppm } \\
\hline & & & & & \multicolumn{2}{|c|}{ Infant formula } & \multicolumn{2}{|c|}{ Follow-up formula } \\
\hline & & & & & Hydrolysis & Non-hydrolysis & Hydrolysis & Non-hydrolysis \\
\hline $\mathrm{C} 0$ & 161.1995 & 161.1052 & 162.1131 & $\begin{array}{c}162.1142 \\
(-6.8)\end{array}$ & $\begin{array}{c}162.1138 \\
(-4.3)\end{array}$ & $\begin{array}{c}162.1140 \\
(-5.6)\end{array}$ & $\begin{array}{c}162.1135 \\
(-2.5)\end{array}$ & $\begin{array}{c}162.1143 \\
(-7.4)\end{array}$ \\
\hline $\mathrm{C} 2$ & 203.2363 & 203.1158 & 204.1236 & $\begin{array}{c}204.1251 \\
(-7.3)\end{array}$ & $\mathrm{ND}^{\mathrm{d}}$ & $\begin{array}{c}204.1249 \\
(-6.4)\end{array}$ & ND & $\begin{array}{c}204.1255 \\
(-9.3)\end{array}$ \\
\hline $\mathrm{C} 3$ & 217.2628 & 217.1314 & 218.1392 & & ND & $\begin{array}{c}218.1409 \\
(-7.8)\end{array}$ & ND & $\begin{array}{c}218.1409 \\
(-7.8)\end{array}$ \\
\hline $\mathrm{C} 4$ & 231.2892 & 231.1471 & 232.1549 & & ND & $\begin{array}{c}232.1568 \\
(-8.2)\end{array}$ & ND & $\begin{array}{c}232.1571 \\
(-9.5)\end{array}$ \\
\hline C5 & 245.3157 & 245.1627 & 246.1705 & & $\begin{array}{c}246.1721 \\
(-6.5)\end{array}$ & $\begin{array}{c}246.1704 \\
(-0.4)\end{array}$ & $\begin{array}{c}246.1696 \\
(-3.7)\end{array}$ & $\begin{array}{c}246.1720 \\
(-6.1)\end{array}$ \\
\hline C6 & 259.3421 & 259.1784 & 260.1862 & & ND & ND & ND & ND \\
\hline C7 & 273.3686 & 273.1940 & 274.2018 & & ND & ND & ND & ND \\
\hline $\mathrm{C} 8$ & 287.3951 & 287.2097 & 288.2175 & $\begin{array}{c}288.2198 \\
(-7.9)\end{array}$ & ND & $\begin{array}{c}288.2185 \\
(-3.5)\end{array}$ & ND & $\begin{array}{c}288.2211 \\
(-12.5)\end{array}$ \\
\hline C9 & 301.4215 & 301.3353 & 302.2331 & & ND & ND & ND & ND \\
\hline $\mathrm{C} 10$ & 315.4480 & 315.2410 & 316.2488 & & ND & ND & ND & ND \\
\hline $\mathrm{C} 11$ & 329.4744 & 329.2566 & 330.2644 & & ND & ND & ND & ND \\
\hline $\mathrm{C} 12$ & 343.5009 & 343.2722 & 344.2801 & & ND & ND & ND & ND \\
\hline C13 & 357.5274 & 357.2879 & 358.2958 & & ND & ND & ND & ND \\
\hline $\mathrm{C} 14$ & 371.5538 & 371.3036 & 372.3114 & & ND & ND & ND & ND \\
\hline $\mathrm{C} 15$ & 385.5803 & 385.3192 & 386.3271 & & ND & ND & ND & ND \\
\hline
\end{tabular}

a. Molecular weight. b. Analysis of standard solutions $(\mathrm{C} 1, \mathrm{C} 2$, and C8). c. The relative mass accuracy, $(\mathrm{m} / \mathrm{z}$ (experimental) $-\mathrm{m} / \mathrm{z}$ (calculated)) $/ \mathrm{m} / \mathrm{z}$ (calculated), is given in parts per million ( $\mathrm{ppm})$. d. Not detected is "peak abundance is $<5000$ ".

phase B was $100 \mathrm{mM}$ ammonium formate aqueous solution/ acetonitrile $(50: 50, \mathrm{v} / \mathrm{v})$. The appearance of L-carnitine peak is singular and symmetric at $3.53 \mathrm{~min}$. The IS (L-carnitine- $d_{3}$ ) peak demonstrates chromatographic behavior that matches that of native L-carnitine (Fig. S1, Supporting Information).

The MS conditions were initially developed by analyzing L-carnitine and IS solutions in the ESI-positive mode, which confirmed the predominant $[\mathrm{M}+\mathrm{H}]^{+}$ions at $\mathrm{m} / z 162$ and 165 for L-carnitine and the IS, respectively. The $[\mathrm{M}+\mathrm{H}]^{+}$ions were chosen as precursor ions for ESI-MS/MS analysis and resulted in fragmentation of the parent $[\mathrm{M}+\mathrm{H}]^{+}$ions into product ions. The transitions of $\mathrm{m} / \mathrm{z}, 162>85$ and $162>103$ were chosen for MRM of L-carnitine because the $\mathrm{m} / \mathrm{z}, 85$ and 103 ions were the most intense in the product ions. Similarly, the ion transitions of $m / z, 165>85$ and $165>103$ were chosen for MRM of the IS. A single peak appeared at $3.47-3.58 \mathrm{~min}$ in all chromatograms, which confirmed the presence of L-carnitine in the milk samples. There was no interfering peak in any chromatogram despite minimal sample cleanup (Fig. S2, Supporting Information). The MRM chromatograms for the IS were similar and showed no interfering peak. Signal suppression of approximately $2-3 \%$ typically occurred when the hydrolyzed samples were analyzed, but the change in signal intensity was corrected against the IS.

\section{Method validation}

Linearity was evaluated for L-carnitine at $8-320 \mathrm{ng} / \mathrm{mL}$ by using 6-point standard curves. Table 2 shows the average results for least-squares linear regression analysis of the standard curves $(n=10)$. Linearity was obtained for L-carnitine with a corresponding correlation coefficient $>0.999$. Precision of the developed analytical method was determined by calculating
Table 2 Results for least-squares linear regression analysis of L-carnitine standard curves $(n=10)$

\begin{tabular}{lccc}
\hline & Slope & Intercept & $r^{2}$ \\
\hline Mean & 0.9146 & 1.0586 & 0.9999 \\
SD & 0.0219 & 0.4933 & 0.0001 \\
\hline
\end{tabular}

Table 3 Repeatability values from unspiked milk samples

\begin{tabular}{lcc}
\hline \multicolumn{1}{c}{ Milk sample } & $\begin{array}{c}\text { L-carnitine } \\
\text { concentration/mg } \\
100 \mathrm{~g}^{-1 \mathrm{a}}\end{array}$ & RSD, \% \\
\hline SRM 1849a & $13.9 \pm 0.6$ & 4.5 \\
Infant formula & $10.4 \pm 0.4$ & 4.0 \\
Follow-up formula & $14.5 \pm 0.5$ & 3.3 \\
Whey protein concentrate powder & $82.4 \pm 1.7$ & 2.1 \\
Whole milk powder & $15.7 \pm 0.4$ & 2.5 \\
Skim milk powder & $20.7 \pm 0.7$ & 3.3
\end{tabular}

a. Number of replicates: $2 \times 6$. Values represent means \pm SD.

repeatability. Repeatability was calculated from the analyses of infant formula, follow-up formula, raw materials, and SRM 1849a in duplicate on each of six days. The overall method RSDs were $<5 \%$ (Table 3). Accuracy was evaluated by analysis of SRM 1849a. The value of SRM 1849a by our method was $13.9 \pm 0.6 \mathrm{mg} / 100 \mathrm{~g}$, with an RSD value of $4.5 \%$ (Table 3 ). Comparison with the SRM value $(13.6 \pm 1.4 \mathrm{mg} / 100 \mathrm{~g})$ showed equivalence. The accuracy was also based on the recovery of 
Table 4 Recovery values from spiked milk samples ${ }^{\mathrm{a}}$

\begin{tabular}{lccccc}
\hline \multirow{2}{*}{ Milk sample } & \multicolumn{2}{c}{$\begin{array}{c}\text { Spiked } \\
\text { L-carnitine }\end{array}$} & & \multicolumn{2}{c}{$\begin{array}{c}\text { Spiked } \\
\text { acetyl-L-carnitine }\end{array}$} \\
\cline { 2 - 3 } & Recovery, \% ${ }^{\mathrm{d}}$ & RSD, \% & & Recovery, \% & RSD, \% \\
\hline Infant formula & $93.4 \pm 3.7$ & 4.0 & & $104.1 \pm 6.4$ & 6.1 \\
Follow-up formula & $93.4 \pm 3.3$ & 5.3 & & $104.1 \pm 9.3$ & 8.3 \\
Whey protein & $94.2 \pm 3.4$ & 3.6 & & $109.3 \pm 5.8$ & 5.3 \\
$\begin{array}{l}\text { concentrate powder } \\
\text { Whole milk powder }\end{array}$ & $91.8 \pm 4.9$ & 5.3 & & $98.9 \pm 8.2$ & 8.3 \\
Skim milk powder & $90.2 \pm 3.9$ & 4.4 & & $103.2 \pm 6.7$ & 6.5 \\
\hline
\end{tabular}

a. Number of replicates: $2 \times 3$. b. Spike level: $100 \%$ of the L-carnitine amount in each unspiked milk powder. c. Spike level: $100 \%$ of the L-carnitine amount in each unspiked milk powder. d. Values represent means \pm SD.

Table 5 Total L-carnitine content in commercial infant formulas and follow-up formulas

\begin{tabular}{ccc}
\hline Product $^{\mathrm{a}}$ & $\begin{array}{c}\text { Total L-carnitine } \\
\text { concentration/mg } 100 \mathrm{~g}^{-1} \mathrm{~b}\end{array}$ & $\begin{array}{c}\text { Label claim } \\
\text { concentration/mg } 100 \mathrm{~g}^{-1}\end{array}$ \\
\hline 1 & 10.2 & 10.0 \\
2 & 11.2 & nd \\
3 & 3.8 & nd \\
4 & 9.5 & nd \\
5 & 9.6 & 10.0 \\
6 & 14.4 & 14.4 \\
7 & 9.3 & nd \\
8 & 8.0 & nd \\
9 & 6.2 & nd \\
10 & 8.6 & nd \\
11 & 14.1 & 10.0 \\
12 & 10.7 & 10.0 \\
\hline
\end{tabular}

a. $1-6$ are infant formulas and $7-12$ are follow-up formulas. b. Mean, $n=3$. c. nd: not declared.

L-carnitine content from infant formula, follow-up formula, and raw materials overspiked with L-carnitine at approximately $100 \%$ of the unspiked L-carnitine concentrations. The overall mean recoveries of L-carnitine were between 90.2 and $94.2 \%$, with RSD values between 3.6 and $5.3 \%$. The accuracy of the total L-carnitine determination was ascertained by overspiking with acetyl-L-carnitine. In addition, we used acetyl-L-carnitine to assess the completeness of the hydrolysis procedure and the accuracy of the total L-carnitine determination. Acetyl-Lcarnitine was overspiked into samples at a concentration that would provide a free L-carnitine concentration of approximately $100 \%$ of that in each unspiked sample after hydrolysis. The overall mean recoveries of acetyl-L-carnitine content were between 98.9 and $109.3 \%$, with RSD values between 5.3 and $8.3 \%$ (Table 4 ). Recovery values of spiked acetyl-L-carnitine were approx. $10 \%$ higher than those of spiked L-carnitine. We have reported the stability of L-carnitine under the hydrolysis conditions; $0.2 \mathrm{M} \mathrm{KOH}$ solution at $40^{\circ} \mathrm{C}$ for $60 \mathrm{~min},{ }^{13}$ but several percent of L-carnitine was degraded. In case of spiked acetyl-L-carnitine, the hydrolysis was terminated when the free L-carnitine was produced from acetyl-L-carnitine. On the other hand, spiked L-carnitine was degraded a few percent during the hydrolysis process. We thought that a few percent degradation of the L-carnitine emerged as the difference between the recovery values.
Determination of total L-carnitine content in commercial infant formulas and follow-up formulas

The twelve various commercial formulas were assayed, and the total L-carnitine content is presented in Table 5 together with declared label claim when available. The formulas had diverse total L-carnitine content ranging from 3.8 to $14.4 \mathrm{mg} / 100 \mathrm{~g}$ because of their complex and varied compositions.

\section{Conclusions}

In conclusion, our method is sensitive, reliable, can be easily performed, does not require the use of ion-pairing reagents, and can be successfully applied to the determination of total L-carnitine content in infant formula, follow-up formula, and raw materials. The assay is rapid and useful for routine measurement of total L-carnitine content in various infant formulas and quality control samples.

\section{Acknowledgements}

We are highly appreciative of Ms. Y. Osame and Mr. H. Takayashiki (Wakodo Co., Ltd.) for their contributions.

\section{Supporting Information}

Supporting information shows MRM chromatograms of L-carnitine and IS. This material is available free of charge on the Web at http://www.jsac.or.jp/analsci/.

\section{References}

1. C. J. Rebouche, FASEB J., 1992, 6, 3379.

2. A. G. Feller and D. Rudman, J. Nutr., 1988, 118, 541.

3. D. C. Woollard, H. E. Indyk, and G. A. Woollard, Food Chem., 1999, 66, 121.

4. J. Demarquoy, B. Georges, C. Rigault, M. C. Royer, A. Clairet, M. Soty, S. Lekounoungou, and F. Le Borgne, Food Chem., 2004, 86, 137.

5. C. Campoy, R. Bayés, J. M. Peinado, M. Rivero, C. López, and J. A. Molina-Font, Early Hum. Dev., 1998, 53, S149.

6. A. Sandor, K. Pecsuvac, J. Kerner, and I. Alkonyi, Pediatr. Res., 1982, 16, 89.

7. Y. Ohtani, A. Higashi, and I. Matsuda, J. Pediatr. Gastroenterol. Nutr., 1985, 4, 845.

8. P. R. Borum, C. M. York, and H. P. Broquist, Am. J. Clin. Nutr., 1979, 32, 2272.

9. M. Hamamoto, K. Shimoda, N. Matsuura, and H. Matsuura, J. Jpn. Soc. Nutr. Food Sci., 1988, 41, 397.

10. D. W. La Count, J. K. Drackley, and D. J. Weigel, J. Dairy Sci., 1995, 78, 1824.

11. D. C. Woollard, H. E. Indyk, and G. A. Woollard, Food Chem., 1997, 59, 325.

12. M. Hamamoto, K. Shimoda, N. Matsuura, and H. Matsuura, J. Jpn. Soc. Nutr. Food Sci., 1988, 41, 389.

13. I. Nadaoka, E. Hatakeyama, T. Akiba, S. Fukaya, and Y. Yamano, Milk Science, 2013, 62, 23.

14. N. R. Marquis and I. B. Fritz, J. Lipid Res., 1964, 5, 184.

15. N. Takeyama, D. Takagi, K. Adachi, and T. Tanaka, Anal. Biochem., 1986, 158, 346.

16. N. Arakawa, T. Y. Ha, and M. Otsuka, J. Nutr. Sci. Vitaminol., 1989, 35, 475. 
17. P. E. Minkler, M. S. Stoll, S. T. Ingalls, S. Yang, J. Kerner, and C. L. Hoppel, Clin. Chem., 2008, 54, 1451.

18. D. E. Starkey, J. E. Denison, C. T. Seipelt, and W. A. Jacobs, J. AOAC Int., 2008, 91, 130.

19. P. Andrieux, T. Kilinc, C. Perrin, and E. Campos-Giménez, J. AOAC Int., 2008, 91, 777.

20. M. M. Phillips and L. C. Sander, J. AOAC Int., 2012, 95, 1479.

21. X. Liu and C. A. Pohl, J. Chromatogr. A, 2012, 1232, 190.

22. M. Lämmerhofer, M. Richter, J. Wu, R. Nogueira, W. Bicker, and W. Lindner, J. Sep. Sci., 2008, 31, 2572.
23. E. Apfelthaler, W. Bicker, M. Lämmerhofer, M. Sulyok, R. Krska, W. Lindner, and R. Schuhmacher, J. Chromatogr. A, 2008, 1191, 171.

24. X. Liu, C. Pohl, A. Woodruff, and J. Chen, J. Chromatogr. A, 2011, 1218, 3407.

25. X. Liu and C. A. Pohl, J. Sep. Sci., 2010, 33, 779.

26. M. Biba, E. Jiang, B. Mao, D. Zewge, J. P. Foley, and C. J. Welch, J. Chromatogr. A, 2013, 1304, 69.

27. P. G. Stevenson, J. N. Fairchild, and G. Guiochon, J. Chromatogr. A, 2011, 1218, 1822. 